\title{
Toquenitzar el català: la llengua com a bé comú
}

\author{
Marta Poblet ${ }^{\mathrm{a}}$ i Pompeu Casanovas ${ }^{\mathrm{bc}}$ \\ ${ }^{a}$ RMIT University, Melbourne, Austràlia \\ ${ }^{\mathrm{b}}$ La Trobe University, Melbourne, Austràlia \\ 'Institut de Dret i Tecnologia (IDT-UAB)
}

Col·loquis de Vic 2020

Societat Catalana de Filosofia, IEC

[Versió 5 de desembre de 2020]

A John Berger (1926-2017) i Douglas N.
Walton (1942-2020), in memoriam

\section{Un canvi radical}

El diàleg té molts vessants, i és un dels temes més antics de la filosofia. Dia-logos, dialogar és raó compartida, enraonar. Els filòsofs, des dels mimes de Sofró, els estoics, el mètode socràtic, els diàlegs de Plató, els topoi d'Aristòtil, l'oratòria de Ciceró i la retòrica de Quintilià, han estudiat l'art del diàleg per dins i per fora. Han disseccionat la interacció comunicativa, oral o escrita de totes les formes possibles. Han distingit entre l'"art de trobar veritats", que diria Llull, i l'art de la deducció. La inventio i la deductio. Enmig, la compositio i la elocutio. Tant la retòrica com la dialèctica s'han ocupat de la narració compartida del diàleg a partir de la seva elaboració, del seu contingut, de la seva estructura, dels seus efectes, del seu impacte. Avui dia, tant la pragmàtica com l'anàlisi dels discurs segueixen els seus passos. I tots els papers de l'auca han passat als llenguatges de la intel-ligència artificial, a la lògica i a les ciències del disseny i de la computació. La teoria i models formals de l'argumentació han vingut a ocupar metodològicament el lloc de la dialèctica i la retòrica. Als anys vuitanta i noranta la pragma-dialèctica i la lògica informal van donar lloc a la teoria de l'argumentació i les aplicacions en intel-ligència artificial (Eemeren i Grootendors 2004).

Però el tipus de preguntes que voldríem fer en aquesta comunicació té un vessant més existencial i no afecta (o no tant) a l'anàlisi del diàleg com a la qüestió igualment bàsica de la llengua parlada. Es refereix al diàleg com a forma de vida, com a actitud, com a expressió, i com a constant. També es refereix a la innovació, i específicament a la innovació cultural. És a dir, a com podem inventar literalment noves formes de relacionarnos amb la cultura, amb la llengua i amb nosaltres mateixos. Això comença a ser urgent, perquè estem convençuts que ens trobem en un període de canvi radical, un dels escassos moments en què es produeix una fractura decisiva entre èpoques passades i la present. Això tampoc és nou: les ruptures es van donar en diferents moments històrics per la introducció de noves tècniques d'escriptura, d'expressió i d'impressió; i també per les condicions estructurals que emmarcaven la coordinació de les accions dels individus i la seva institucionalització. Autors tan diversos entre si com Walter Ong, Jack Goody, Karl Polanyi, Douglas North, Elinor Ostrom i Joshua Ober ens poden ajudar a entendre aquest fenomen. Hem entrat de ple en l'era digital, i.e. en la civilització digital.

El raonament serà el-líptic perquè volem presentar la idea precisa de toquenitzar el català, i abans d'arribar-hi ens agradaria deixar clar el marc del qual partim: la nostra vida 
quotidiana, la llengua que parlem cada dia, les amistats que tenim i que inevitablement anem deixant pel camí. No res intel-lectual: senzillament la vida que compartim en una societat que ja és radicalment distinta de la que havíem conegut abans. Si això es cert, ens reflectim en els petits trossos d'un mirall trencat, i ja no podem tornar-los a aplegar en un tot: és millor construir-ne un de nou.

John Berger ha estat un dels artistes contemporanis que ha insistit més en aquest tema. Sense fer-se notar, amb elegància i deferència. Berger parlava sempre dels seus amics, amb qui mantingué una comunicació fluida durant cinquanta anys o més. Els recordava en els seus escrits ocasionals $i$ hom pot sentir l'estima i la comprensió amb què els tenia. Perfectament conscient del lloc i el temps en què vivia, dibuixava, escrivia, conversavatot al mateix temps - en una mena de diàleg interior que compartia amb el lector. Parlava amb i dels seus amics, molts d'ells desconeguts o almenys no reconeguts en el mercat de l'art, pel que feien i pel que eren. Dibuixava similituds; es preguntava per la natura com a text; trobava analogies sorprenents, de contingut i forma. I el que dibuixava esdevenia real, i no cap còpia de res.

"Un llenguatge parlat és un cos, una criatura viva, la fisiognomia de la qual és verbal i les funcions de la qual són lingüístiques. I la llar d'aquesta criatura és tant allò que és inarticulat com allò articulat" (Berger 2016: 5).

Hi ha alguna cosa indivisible, única, intransferible, que possibilita el diàleg. Es refereix a allò que som, que hi és, i que de vegades no podem dir ni compartir, aquest humus singular canviant que portem a dins i que pot prendre la forma dels mots en una llengua, però que moltes més vegades roman sense dir, expressable d'una altra manera, en gestos, en silencis o senzillament en una forma d'estar i posicionar-se davant de les coses i dels altres. Des d'aquesta perspectiva, el vessant normatiu de la dialèctica queda en suspens, s'atura: no serveix per a avaluar perquè no es pretén convèncer ningú, ni es pensa en una audiència, ni es necessita cap comprensió negociada, ni existeix cap obligació sobrevinguda o derivativa, ni es vol expressar amb precisió cap contingut compartit. No hi ha temps ni espai per això. No precisa de cap esquema cognitiu o cultural, ni de cap de les formes conegudes d'argumentació que Douglas Walton (2016) denominava "esquemes d'argumentació" i va explorar i descriure durant tota la seva vida intel-lectual. Tampoc necessitem estructurar metadades a partir d'un llenguatge formal de marcatge. Els llenguatges semàntics serveixen justament per articular després, si fem servir l'expressió de Berger.

Però apedaçar — ja ho hem avançat — no serveix de gaire quan el que s'ha de fer és un vestit nou. Enfrontar-nos a un món totalment digital és enfrontar-nos a nosaltres mateixos, començant per la llengua que fem servir i acabant per tots els aspectes de la cultura que construïm.

El món que ens espera presenta condicions molt diferents de les que ara tenim. La comunicació és globalment escalable, i les tècniques d'Intel-ligència Artificial només han fet que començar. ¿Què passarà amb les llengües naturals minoritàries? I més concretament, què passarà amb el català? És la noció de 'política lingüística' suficient per a enfrontar-nos a aquest nou context basat en les teories de la informació i les tècniques computacionals? Què es pot fer perquè el futur del català "depengui de tu", com apunta el darrer llibre de la lingüista Carme Junyent (2000)?

Just abans d'aquesta època digital, la fenomenologia i l'hermenèutica del segle XX, especialment en el període d'entreguerres i després de la segona gran guerra, van prendre bona nota de què significava experimentar canvis estructurals perquè el conflicte va fer emergir la necessitat del contacte i també va fer palesa la profunditat de les diferències entre cultures, religions i persones. Des d'aquest punt de vista, compartir la llengua, i especialment compartir-la de forma híbrida (i.e. no 'pura') i lliure (i.e. no 'controlada'), és és important perquè proporciona l'espai comú a partir de què poden emergir propietats 
noves i inesperades. Breu, n'assegura l'evolució i la supervivència. Bàsicament: que se segueixi parlant. Aquest és el primer objectiu quan les condicions canvien.

Hi ha una bona colla de lingüistes, filòlegs, sociolingüistes i historiadors de la literatura preocupats amb aquesta qüestió a Catalunya. Ens atreviríem a dir que la totalitat. En un o altre moment, tots es plantegen el tema. Nosaltres no tenim, certament, cap vareta màgica. La nostra, més que una proposta, és una intuïció del que es podria fer, ja que les institucions socials tindran cada cop un lloc més preeminent en la societat digital.

\section{La llengua com a bé comú}

Les llengües es defineixen sovint com a objecte, bé, recurs, o patrimoni. I, en bona mesura, totes aquestes aproximacions són compatibles entre si. Ara bé, quin tipus d'objecte, bé, recurs o patrimoni defineix una llengua? Aquí podem establir algunes diferències importants. Per a il-lustrar-les, ens anirà be considerar la tipologia, avui àmpliament utilitzada, que Elinor i Vincent Ostrom van proposar l'any 1978 en el marc dels seus estudis d'economia política i institucional.

La tipologia de béns dels Ostrom (1978) parteix de dos criteris: accessibilitat (quin grau d'accés tenim al bé) i rivalitat (quin grau d'exclusió suposa el nostre consum per al consum dels altres). Així, per exemple, l'aire que respirem, o una posta de sol, són bens públics: l'accés és lliure i el gaudi és no-competitiu (tots en podem gaudir sense excloure'ns els uns als altres). En la direcció oposada hi tenim els béns privats (d'ús restringit i exclusiu per als propietaris). Entremig, hi ha dos béns de caràcter híbrid. D'una banda, els béns de club, o d'ús restringit (se'n pot restringir l'accés fàcilment-per exemple, pagant una subscripció - però se'n pot gaudir amb d'altres membres de forma no rival). D'altra, hi ha els béns comuns, l'accés als quals és més difícil de delimitar, i on l'ús, a més, té un component d'exclusió o de rivalitat (per exemple, recursos naturals com els aqüífers, els regadius, les pastures, els boscos, etc.). Tant és així que els casos d'ús indiscriminat d'aquest recursos duen al que Hardin (1968) va qualificar com la "tragèdia dels béns comuns", és a dir, a la seva desaparició per sobreexplotació.

El que els estudis d'Elinor Ostrom mostren, tanmateix, és que la tragèdia dels béns comuns no és inevitable. La gestió sostenible d'aquest recursos és possible si les comunitats que se'n beneficien els gestionen de forma eficient. Després d'analitzar molts casos de gestió de béns comuns arreu del món, Ostrom va extreure vuit principis que, en menor o major mesura, són presents en tots els sistemes de gestió sostenible. De forma sintètica: (i) límits definits; (ii) monitorització efectiva dels comportaments; (iii) sancions graduades; (iv) proporcionalitat entre costos i beneficis; (v) mecanismes de resolució de conflictes; (vi) reconeixements del drets d'autoorganització; (vii) mecanismes de decisió col·lectiva o consens; (vii) subsidiarietat i/o estructures policèntriques (Ostrom 1990). Això no casa necessàriament amb el cas de les llengües — no és el que Ostrom tenia en ment. Però, de fet, si apliquem la tipologia inicial de béns al cas de les llengües naturals veurem que hi ha diverses aplicacions interessants possibles pel que fa al català.

Com tantes altres llengües al món, el català ha estat tractat sovint com a bé públic. A Catalunya, això és així des dels anys vuitanta, quan es van encetar les campanyes de normalització lingüística. "El català, cosa de tots", deia el personatge de Norma l'any 1982. Les polítiques lingüístiques del govern de Catalunya de les darreres quatre dècades han partit de la premissa de la llengua com a be públic en un context particular de co-oficialitat, bilingüisme, o diglòssia, segons la perspectiva que es miri. El català com a be públic vol dir que ha de ser accessible i no-excloent, com l'aire que respirem, i que cal procurar-ne aquesta continuïtat (de la mateixa manera que un govern també ha de vetllar continuadament per la qualitat atmosfèrica de l'aire). 
Els encerts i desencerts de les polítiques lingüístiques de les darreres dècades són objecte d'un debat que depassa clarament els marges d'aquestes ratlles. El que volem fer notar aquí, però, és que en d'altres ocasions la llengua es concep, no tant com a bé públic en el sentit dels Ostrom, sinó com a be comú, com a recurs compartit i gestionat per la comunitat de parlants. Aquest tret s'accentua amb l'emergència del món digital, que permet tractar la llengua com un comú digital, és a dir, com a objecte digital articulat i gestionat per comunitats en línia. La idea de béns comuns digitals ['digital commons'] no és nova i, de fet, la mateixa Ostrom se'n fa ressò en la darrera etapa de la seva obra (Hess i Ostrom 2007). Exemples de comuns digitals (i de comunitats que es creen al seu voltant) són el programari lliure, les viquipèdies, les dades obertes, la ciència oberta, les llicencies obertes o, com hem mostrat darrerament amb en Carles Sierra, l'ajuda mútua (Poblet i Sierra 2020).

Els comuns digitals no són una transposició exacta del seu equivalent en el món dels recursos naturals. El perill de sobreexplotació de recursos digitals, especialment si es poden replicar amb facilitat, és molt menor. De fet, els comuns digitals tenen la propietat inversa: com més es fan servir, més creixen, i a l'inrevés. Val a dir que les llengües són un cas especial, ja que mantenen aquesta propietat en tots els àmbits: els comportaments extractius no disminueixen el recurs. Ben al contrari, com més extraiem del 'comú lingüístic', més l'acabem enriquint.

El creixement dels comuns digitals per l'efecte xarxa, no obstant, no en garanteix la sostenibilitat, i els mateixos principis de gestió sostenible que hem esmentat més amunt segueixen sent rellevants aquí. En aquest sentit, el cas de les viquipèdies és il·lustratiu. Les darreres dades disponibles ${ }^{1}$ mostren que la Viquipèdia catalana, creada l'any 2001 (la tercera en crear-se després de les versions anglesa i alemanya) és la vintena del món pel nombre total d'articles (sobre un total de 304 viquipèdies), i la cinquena edició en llengua romànica. ${ }^{2}$ La comunitat de viquipedistes, a més, és activa en diversos àmbits. L'any 2008, aquesta activitat va dur a la creació de l'Amical Wikimedia per a promoure la Viquipèdia $\mathrm{i}$ tots els projectes desenvolupats en paral $\cdot 1 \mathrm{lel} .^{3}$

Peter Gerrand (2009) ja va documentar que els recursos digitals — i concretament la Viquipèdia - són amplament emprats per les llengües minoritàries justament, entre altres coses, per enfortir-les. La digitalització és avui un component essencial de la diversitat lingüística i cultural. La identitat contemporània es conjuga en plural, identitats (Casanovas, Corretger, Salvador, 2019). I de la mateixa manera que la sostenibilitat dels recursos aconsella evitar els monocultius, el veïnatge digital no promou el monolingüisme. Però això no vol dir que la identitat, supervivència, evolució i consistència de les llengües minoritàries s'hagin de deixar a l'atzar. Ben a l'inrevés. Els mapes topològics de Barabassi (2001) han dibuixat una xarxa el grau de distribució de la qual segueix una llei de potència on els nuclis més petits alimenten els més forts. Es discuteix si és una xarxa lliure d'escala. Però és clar que la resposta dels parlants és social i col-lectiva, i.e. institucional en un sentit més comunal que no pas polític. Res no obliga a reduir la identitat lingüística. Dit d'una altra manera, les llengües poden fer-se més fortes a partir justament de la diversitat i pluralitat cultural. I.e. a partir de la seva policentricitat. El que cal, doncs, és facilitar-ne la creació i expansió en les comunitats que les empren.

\footnotetext{
${ }^{1}$ https://meta.wikimedia.org/wiki/List_of_Wikipedias/ca

${ }^{2}$ Vegeu https://ca.wikipedia.org/wiki/Viquip\%C3\%A8dia_en_catal\%C3\%A0 . Com recorda la pròpia Viquipèdia, el primer article de parla no anglesa que s'ha editat mai és el de l'àbac (en català) ${ }^{3}$ Vegeu https://www.wikimedia.cat/
} 


\section{El Web de les Dades}

La tercera generació de la xarxa té encara altres conseqüències per a la digitalitat dels objectes i, com veurem, de les llengües en particular. L'expressió Web 3.0 es refereix al Web de les Dades — les dades com a objecte digital—i també s'aplica al Web Semàntic_els conceptes com a objecte digital $i$, alhora, com a part d'ontologies generals i de dominis específics. Darrerament, el Web 3.0 també fa referencia al web descentralitzat, i en particular a l'emergència de la tecnologia del blockchain o cadena de blocs. La tecnologia de la cadena de blocs permet crear xarxes descentralitzades de transaccions (els blocs) que es validen i s'enllacen mitjançant el consens successiu (la cadena) al qual arriben de forma automàtica una majoria de nodes de la xarxa. El consens distribuït, la immutabilitat de les transaccions validades per la xarxa, i la transparència de tota la cadena són els trets característics de la cadena de blocs.

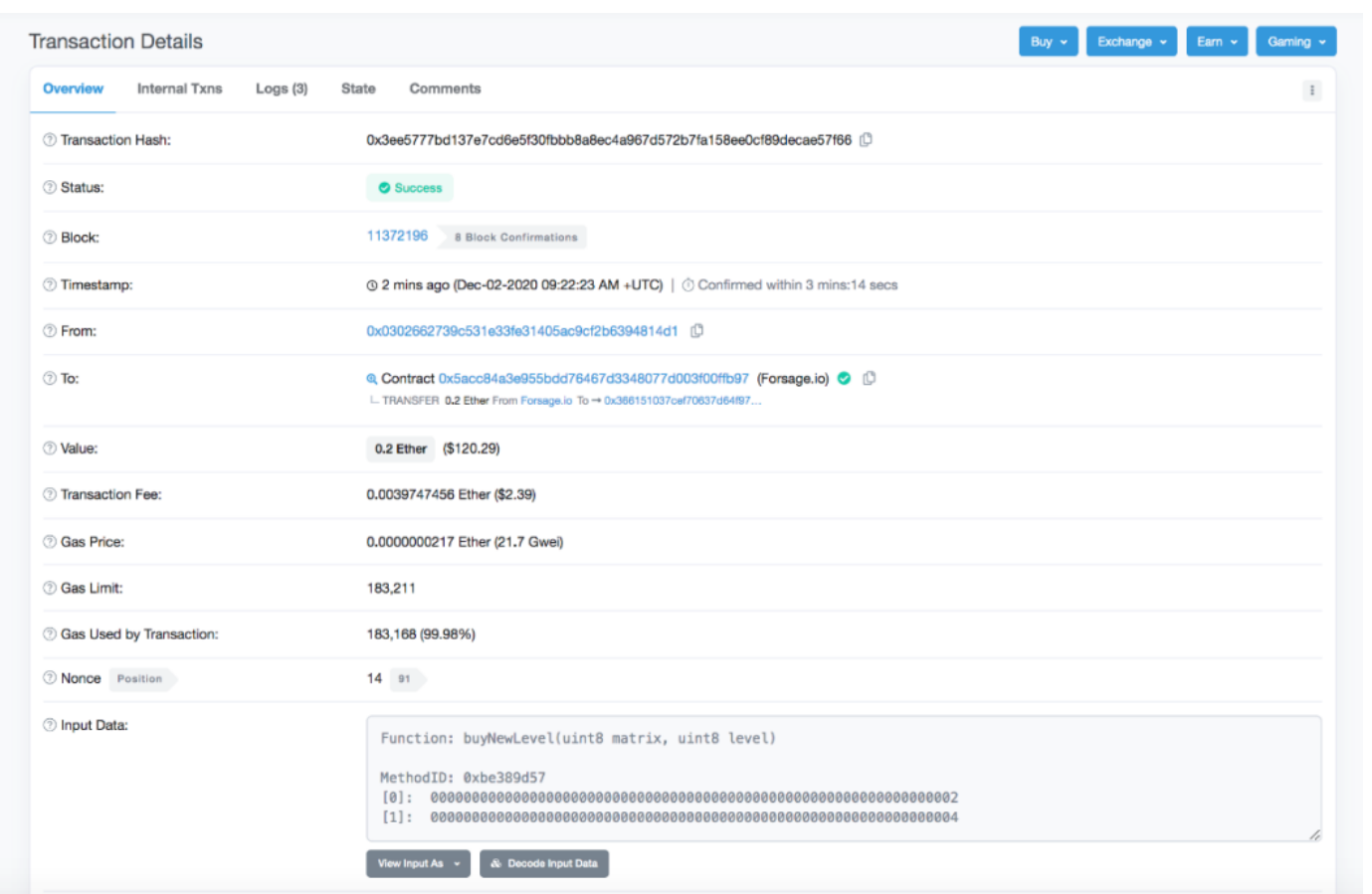

Fig. 1. Exemple de transacció a la plataforma Ethereum

L'aplicació més coneguda de la cadena de blocs és la criptomoneda fundacional, Bitcoin, difosa de forma pseudònima per Satoshi Nakamoto l'any 2008 a través d'una llista de correu electrònic d'experts en criptografia (Nakamoto 2008). Però, especialment des de 2014 i amb la creació de la plataforma Ethereum, la cadena de blocs s'expandeix amb noves capes d'aplicacions, com ara els contractes de codi executable (smart contracts), ${ }^{4}$ el "oracles" que verifiquen dades externes (Poblet et al. 2020), o les organitzacions autònomes descentralitzades (DAOs, de l'anglès "Decentralised Autonomous Organisation").

\footnotetext{
${ }^{4}$ La traducció habitual de smart contract és "contracte intel-ligent". Tanmateix, la característica rellevant d'aquest programari és que s'executa automàticament quan es donen determinades circumstancies i no tant que el codi s'executi de forma intel-ligent o mitjançant algorismes d'intel-ligència artificial. El mateix fundador d'Ethereum, Vitalik Buterin, va lamentar l'ús de l'expressió "smart contract" per a referir-se al que va proposar d'anomenar, mes acuradament, 'línies $\begin{array}{llll}\text { de codi } & \text { persistent' ('persistent } & \text { scripts'). } & \text { Vegeu }\end{array}$
} https://twitter.com/VitalikButerin/status/1051160932699770882 
Els DAOs —el primer dels quals va fracassar en ser víctima d'un atac — ${ }^{5}$, es posen en marxa quan un grup o una comunitat reduïda d'usuaris decideix posar en comú recursos sovint, fons per a finançar d'altres projectes - que es poden gestionar de forma automàtica a partir de codi executable i, quan així s'estableixi, mitjançant diferents mecanismes de votació dels seus membres. Els membres d'un DAO solen rebre tokens en funció de la seva aportació a la liquiditat (liquidity tokens) i a la governança (governance tokens) de la plataforma. Els DAOs, en aquest sentit, generen i mantenen una criptoeconomia i una governança pròpies $i$, de forma creixent, un règim propi de resolució de conflictes (Allen et al. 2020).

Com veiem, la tecnologia de la cadena de blocs introdueix un nou objecte digital, el token. Un 'tóquen', si se'ns permet l'anglicisme i l'accent diacrític, és la representació digital d'una transacció, d'un vot, o d'un bé o objecte del món físic que es digitalitza i es subdivideix. Així, es podria toquenitzar la propietat d'una casa, d'una obra d'art, o del contracte d'un basquetbolista de la $\mathrm{NBA}^{6} \mathrm{i}$, de fet, de qualsevol objecte susceptible de fraccionament i transacció. Com ara una llengua.

\section{Un DAO català}

Imaginem una Organització Autònoma Descentralitzada (DAO) que neix amb la finalitat de digitalitzar la llengua catalana de forma distribuïda, immutable i resistent a qualsevol mena de censura. El nou DAO s'integra a l'ecosistema existent de recursos digitals en català (e.g., Viquipèdia, Softcatalà, Termcat, Diccionari IEC, etc.) i, de fet, adopta aquest recursos com a "oracles" a l'hora de validar les seves pròpies transaccions. Qualsevol usuari del DAO pot fer una transacció similar a la de la Figura 1, enviant-hi una paraula o una expressió. Incorpora algun dels oracles esmentats la paraula o l'expressió que un membre de la comunitat vol aportar al DAO? En cas afirmatiu, la transacció es pot validar. Una paraula, un tóquen. Una expressió, un tóquen.

Podríem afegir al DAO paraules noves, com ara 'tóquen', o inventar noves expressions? Això dependrà del que decideixin els membres del DAO amb els mecanismes de deliberació i de votació que hagin triat per als seus processos de decisió. Com es gestionaria la plataforma? Hi haurien tóquens per a la governança? Admetria donacions? Els membres del DAO podrien treballar en diferents tasques pre-programades, com ara traduccions? ${ }^{7}$ Com es determinarien els pagaments? Aquestes són qüestions que el DAO hauria d'establir en el seu document fundacional. Algunes qüestions són expressables en codi autoexecutable, d'altres requereixen deliberació i votació. Un DAO, en definitiva, no és autònom perquè algunes funcions siguin automatitzables, sinó que ho és en el sentit d'Ostrom: els membres defineixen les seves pròpies regles, com evolucionen com a comunitat, com es relacionen amb d'altres comunitats i com dirimeixen els seus conflictes.

Res no obliga als membres a parlar només aquesta llengua. És compatible amb tota la pluralitat de llengües parlades pels membres de la comunitat. Però quan parlen aquesta llengua, resideixen en ella, i la fan créixer i evolucionar. Breu, enforteixen el seu marc de referència.

\footnotetext{
${ }^{5}$ Vegeu https://medium.com/swlh/the-story-of-the-dao-its-history-and-consequences$71 \mathrm{e} 6 \mathrm{a} 8 \mathrm{5} 51 \mathrm{ee}$

${ }^{6}$ Això es el que va fer Steve Dinwiddie dels Brooklyn Nets, tot i que no va aconseguir el nombre d'inversors necessaris per a l'operació. Vegeu https://cointelegraph.com/news/nba-star-sells-just10-of-tokenized-contract

${ }^{7}$ De fet, ja hi ha comunitats emergents de traductors que utilitzen tecnologia de blocs. Vegeu el servei Lingo, llançat en versió beta el novembre de 2020, https://blog.kleros.io/linguodecentralized-translation-platform/
} 
És hora d'anar acabant aquesta elucubració que ha començat amb les distintes formes de diàleg. Volem encetar un diàleg? Inventem. Volem incentivar la cultura? Toquenitzem la llengua. Volem fer evolucionar la llengua? Creem institucions socials noves. Si només operem en les mateixes institucions polítiques que van florir en els estats anteriors a l'era digital, podem acabar parlant exclusivament la llengua dels nostres interlocutors i adoptant el seu marc de referència.

\section{Referències}

Allen, D., Lane, A., Poblet, M. 2019. "The governance of blockchain dispute resolution". Harvard Negotiation Law Review, Vol. 25, 91-120.

Berger, J. 2016. Confabulations, London: Penguin Classics.

Barabassi, A-L. 2003. "Linked: The New Science of Networks". American Journal of Physics 71, 409, https://doi.org/10.1119/1.1538577

Casanovas, P., Corretger, M., Salvador, V. 2019. "Catalan Identities: Literature, Social Commitment, and Political Engagement". The Rise of Catalan Identity: Social Commitment and Political Engagement in the Twentieth Century. Cham: Springer, pp. 118.

Eemeren, F.H. van, Grootendorst, R. 2004. A systematic theory of argumentation: The pragma-dialectical approach. Cambridge: Cambridge University Press.

Gerrand, P.H. 2009. Minority languages on the Internet: Promoting the regional languages of Spain. VDM Verlag.

Hardin, G. 1968. "The tragedy of the commons”. Science, Vol. 162(3859): 1243-1248. DOI: $10.1126 /$ science. 162.3859 .1243

Hess C., Ostrom, E. 2007. Understanding knowledge as a commons. Cambridge: MIT Press.

Junyent, C., Zaballa, B. 2000. El futur del català depèn de tu. Barcelona: La Campana.

Nakamoto, S., 2008. Bitcoin: A peer-to-peer electronic cash system. Manubot, https://git.dhimmel.com/bitcoin-whitepaper/

Ostrom,V., Ostrom, E. 1978. Public Goods and Public Choices. Indiana University, Workshop in Political Theory and Policy Analysis.

Ostrom, E. 1990. Governing the Commons: The Evolution of Institutions for Collective Action. Cambridge University Press. DOI: https://doi.org/10.1017/CBO9780511807763

Poblet, M., Allen, D.W.E., Konashevych, O., Lane, A.M., Diaz Valdivia ,C.A. 2020. From Athens to the Blockchain: Oracles for Digital Democracy. Front. Blockchain 3:575662. DOI: $10.3389 /$ fbloc.2020.575662

Poblet, M., Sierra, C. 2020. Understanding Help as a Commons. International Journal of the Commons, 14(1), 481-493. DOI: http://doi.org/10.5334/ijc.1029

Walton, D. 2016. Argument Evaluation and Evidence. LGTS, Cham: Springer. 